\title{
Prevalence and Molecular Characterization of Group B Streptococcus in Pregnant Women from Hospitals in Ohangwena and Oshikoto Regions of Namibia.
}

Sylvester Rodgers Moyo ( $\nabla$ srmoyo@nust.na )

Namibia University of Science and Technology

Erastus Lafimana Haimbodi

Namibia University of Science and Technology

Munyaradzi Mukesi

Namibia University of Science and Technology

Research article

Keywords: Group B streptococcus, molecular characterization, antimicrobial susceptibility

Posted Date: August 18th, 2020

DOI: https://doi.org/10.21203/rs.3.rs-38355/v1

License: () (i) This work is licensed under a Creative Commons Attribution 4.0 International License.

Read Full License

Version of Record: A version of this preprint was published at BMC Microbiology on August 5th, 2021. See the published version at https://doi.org/10.1186/s12866-021-02283-2. 


\section{Abstract}

\section{Background}

The main purpose of this study was to investigate the prevalence rate, antimicrobial susceptibility patterns and molecular characteristics of Streptococcus agalactiae isolated from pregnant women at 35 weeks of gestation and above, who attended antenatal screening at selected hospitals in Ohangwena and Oshikoto regions of Namibia.

\section{Results}

Twelve (5.7\%) of women screened were colonised by GBS, of which $25.0 \%$ were colonised rectovaginally, $58.0 \%$ vaginally and $17.0 \%$ rectally. No significant association was reported between GBS colonisation and maternal age, habitat, marital status, education, employment, parity, still births and miscarriages ( $P$ values $>0.05$ ). Antimicrobial susceptibility was reported at $100 \%$ for ampicillin, penicillin \& ceftriaxone. Resistance to tetracycline was reported at $100 \%$. Tetracycline resistance gene tet(M) was present in $88.9 \%$ of the isolates only and none of the isolates presented with tet(0). Polysaccharide capsular type la was found in $9(50 \%)$ and $\mathrm{lb}$ was found in $1(5.5 \%)$ of the total isolates. The remaining isolates were not typeable using PCR.

\section{Conclusion}

Streptococcus agalactiae's positive rate was $5.7 \%$ among the pregnant women examined. Sociodemographic and obstetric factors had no influence on GBS colonisation ( $P$ values $>0.05$ ). No resistance was reported to ampicillin, penicillin and ceftriaxone. No sensitivity was reported to tetracycline. Fifty (50\%) of the isolates were capsular type la, $5.5 \%$ were type $\mathrm{lb}$ and $44.4 \%$ were not typeable using PCR.

\section{Background}

Streptococcus agalactiae (S. agalactiae) is a gram-positive bacterium which belongs to the Lancefield Group B streptococcus (GBS). It is part of the normal flora of the gastrointestinal and female genitourinary tracts, and it is present in the genital tract of about $20-60 \%$ of pregnant women ${ }^{1}$. Nearly $20-40 \%$ of healthy women are colonised by GBS, and $50-70 \%$ of infants born to these mothers become infected with it $^{2}$.

Group B streptococcus is a leading cause of neonatal sepsis and meningitis worldwide ${ }^{3}$. It is widely implicated in maternal infections such as endometritis and chorioamnionitis as well as neonatal infections such as pneumonia, meningitis, sepsis and septicaemia ${ }^{4}$. Mortality of GBS in neonates is over $50 \%$ and is particularly high in preterm infants ${ }^{3}$. Vaginal colonisation by GBS during pregnancy is associated with premature delivery and still births ${ }^{1}$. 
The median prevalence of GBS in pregnant women in Africa was reported at $16 \%$ in $2009^{5}$. The prevalence in Windhoek, Namibia was reported at $13.6 \%$ in $2016^{6}$. Furthermore, the colonisation rate in other Southern African countries was reported at $31.6 \%$ in Zimbabwe in $2000^{7}, 37 \%$ in South Africa in $2018^{8 ;}, 21.2 \%$ in Malawi in $2010^{10}$ and $1.8 \%$ in Mozambique in $2008^{11}$.

Most studies done in Africa have shown a uniformity in sensitivity of GBS to penicillin and ampicillin which are the recommended drugs for prophylaxis against GBS. The Centres for Diseases Control and Prevention (CDC) recommends GBS screening in women at 35-37 weeks of gestation. Prophylaxis is given to pregnant women who are colonised by GBS, deliver infants with invasive GBS disease or are of unknown GBS status at delivery to prevent neonatal infection. However, erythromycin \& clindamycin are recommended for patients who are allergic to penicillin ${ }^{12}$. Gene based resistance in GBS is encoded by ermB, ermA, ermTR, mefA, mefE, aphA-3, aad-6, tet(M), tet(0), int-Tn and mreA ${ }^{13}$.

Group B streptococcus is classified into ten common capsular types based on capsular polysaccharide antigens on the surface of the organism. These capsular types are la, Ib, II, III, IV, V, VI, VII, VIII and IX ${ }^{14 ; 15}$. The most prominent capsular types in Southern Africa are type Ia, Ib, II, III and $\mathrm{V}^{16} ; 17 ; 18 ; 7 ; 19 ; 8$. The capsule is the main virulence factor for GBS. The study aimed to determine the prevalence and molecular characteristics of group B streptococcus isolated from pregnant women from selected rural settings of Namibia.

\section{Results}

\section{Prevalence of Group B streptococcus}

A total of 12 out of the 210 participants, (5.7\%) tested positive for GBS colonisation, of which $10(4.8 \%)$ tested positive with vaginal swabs and $5(2.3 \%)$ tested positive with rectal swabs. A total of $3(1.43 \%)$ out of 210 participants tested positive with both rectal and vaginal swabs.

This study assessed the influence of different socio-demographic characteristics, age and obstetric factors on the rate of GBS colonisation in pregnant women screened.

The age of pregnant women screened in this study ranged from 16-49 years with mean age of 29 years and standard deviation of \pm 7 . Out of the total 210 pregnant women, 174 were living in rural, 9 in semiurban and 27 in urban areas. One hundred and sixty (160) women were not married, while 50 were married. Those with qualifications below matric were 156, those with matric qualifications were 51 and those with tertiary qualifications were only 3 . Unemployed women were 168 and employed women were 42.

Out of the twelve colonised women, $75.0 \%$ was women aged between $20-39$ years and $25.0 \%$ was women aged 40 years and above ( $P$ value 0.209$)$. Majority of colonised women were rural based women 
(83.3\%) than urban living women (16.7\%) ( $P$ value 0.708$)$. Unmarried women colonised by GBS were $75.0 \%$ and $25.0 \%$ of colonised women were married ( $P$ value 0.921$)$.

Majority of colonised women were those with educational level below matric (58.3\%) than those with matric qualifications (41.7\%) ( $P$ value 0.333 ). The same scenario was found in terms of employment status, whereby $66.7 \%$ of unemployed women were colonised and only $33.3 \%$ of colonised women were employed ( $P$ value 0.234$)$.

Majority of GBS colonised were unmarried, unemployed and rural based women aged between 2039 years who never matriculated. Table 1 illustrates the rates of GBS colonisation based on various sociodemographic factors.

Table 1

Association between socio-demographic factors and GBS colonisation

\begin{tabular}{|c|c|c|c|c|}
\hline Characteristic & Category & $\begin{array}{l}\text { GBs non-colonised frequency } \\
(n=198)\end{array}$ & $\begin{array}{l}\text { GBS colonised frequency } \\
(n=12)\end{array}$ & $\begin{array}{l}P \\
\text { value }\end{array}$ \\
\hline \multirow[t]{3}{*}{ Age in years } & Below 20 & $12(6.1 \%)$ & $0(0.0 \%)$ & \multirow[t]{3}{*}{0.209} \\
\hline & $20-39$ & $166(83.8 \%)$ & $9(75.0 \%)$ & \\
\hline & $\begin{array}{l}40 \text { and } \\
\text { above }\end{array}$ & 20 (10.1\%) & $3(25.0 \%)$ & \\
\hline \multirow[t]{3}{*}{ Habitat } & Rural & 164 (82.8\%) & 10 (83.3\%) & \multirow[t]{3}{*}{0.708} \\
\hline & Semi-urban & $9(4.5 \%)$ & $0(0.0 \%)$ & \\
\hline & Urban & 25 (12.6\%) & $2(16.7 \%)$ & \\
\hline \multirow[t]{2}{*}{ Marital status } & Not married & 151 (76.3\%) & $9(75.0 \%)$ & \multirow[t]{2}{*}{0.921} \\
\hline & Married & 47 (23.7\%) & $3(25.0 \%)$ & \\
\hline \multirow{3}{*}{$\begin{array}{l}\text { Educational } \\
\text { level }\end{array}$} & Below & 149 (75.3\%) & $7(58.3 \%)$ & \multirow[t]{3}{*}{0.333} \\
\hline & 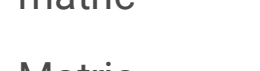 & 46 (23.2\%) & $5(41.7 \%)$ & \\
\hline & Tertiary & $3(1.5 \%)$ & $0(0.0 \%)$ & \\
\hline \multirow{2}{*}{$\begin{array}{l}\text { Employment } \\
\text { status }\end{array}$} & Unemployed & $160(80.8 \%)$ & $8(66.7 \%)$ & \multirow[t]{2}{*}{0.234} \\
\hline & Employed & 38 (19.2\%) & 4 (33.3\%) & \\
\hline
\end{tabular}

Among all GBS colonised women, women of with three or more successful pregnancies were $50.0 \%$, while those with either one or two were $33.0 \%$ and those without any previous pregnancy were $16.7 \%$ ( $P$ value 0.659). Carriage of GBS was only shown in women without previous history of still births ( $P$ value 0.613$)$. GBS colonised women without any history of miscarriages were $83.3 \%$ while those with a history of either 1 or 2 miscarriages were $16.7 \%$ ( $P$ value 0.471 ). Table 2 illustrates the association between obstetric factors and GBS colonisation. 
Table 2

Association between obstetric factors and GBS colonisation

\begin{tabular}{|lllll|}
\hline Characteristic & Category & $\begin{array}{l}\text { GBS non-colonised frequency } \\
(\mathbf{n = 1 9 8 )}\end{array}$ & $\begin{array}{l}\text { GBS colonised frequency } \\
(\mathbf{n = 1 2})\end{array}$ & $\begin{array}{l}\boldsymbol{P} \\
\text { value }\end{array}$ \\
\hline Parity & 0 & $43(21.7 \%)$ & $2(16.7 \%)$ & 0.659 \\
& $1-2$ & $82(41.4 \%)$ & $4(33.3 \%)$ & \\
\hline Still births & 0 & $73(36.9 \%)$ & $6(50.0 \%)$ & 0.613 \\
& $1-2$ & $13(6.6 \%)$ & $12(100 \%)$ & \\
& $\geq 3$ & $2(1.0 \%)$ & $0(0.0 \%)$ & 0.471 \\
\hline Miscarriages & 0 & $178(89.9 \%)$ & $0(0.0 \%)$ & \\
& $1-2$ & $20(10.1 \%)$ & $10(83.3 \%)$ & \\
& $\geq 3$ & $0(0.0 \%)$ & $2(16.7 \%)$ & $0(0.0 \%)$ \\
\hline
\end{tabular}

The culture of rectal and lower vaginal swabs by both direct BCNA agar and Todd-Hewitt-BCNA agar has yielded a total of 18 CAMP positive GBS isolates. These isolates were confirmed as $S$. agalactiae using real time PCR, in which the target gene $s c p B$ for $C 5$ a peptidase gene was amplified. Following gel electrophoresis, DNA amplicons approximately 255 base pairs on the gel were identified as $S$. agalactiae as previously described by Dmitriev et al., 2004. No sequencing was performed in this study.

\section{Antimicrobial susceptibility patterns}

All 18 GBS isolates obtained from this study were tested for antimicrobial susceptibility, and all had shown $100 \%$ susceptibility to penicillin, ampicillin, ceftriaxone, clindamycin, erythromycin, vancomycin, linezolid and chloramphenicol. All isolates revealed $100 \%$ resistance to tetracycline. Intermediary sensitivity and inducible clindamycin resistance were reported for any organism. The frequencies of antimicrobial susceptibility patterns are illustrated in Table 3. 
Table 3

Frequency of antimicrobial susceptibility patterns of GBS isolates

\begin{tabular}{|lllllll|}
\hline \multirow{2}{*}{$\begin{array}{l}\text { Antimicrobial } \\
\text { agent }\end{array}$} & \multicolumn{5}{l}{ Percentage of GBS antibiotics sensitive, intermediate and resistant } \\
\cline { 2 - 7 } & \multicolumn{2}{l}{ Sensitive (S) } & Intermediate (I) & \multicolumn{2}{l|}{ Resistant (R) } \\
\cline { 2 - 7 } & Frequency & Percentage & Frequency & Percentage & Frequency & Percentage \\
\hline Penicillin & 18 & $100 \%$ & 0 & $0 \%$ & 0 & $0 \%$ \\
\hline Ampicillin & 18 & $100 \%$ & 0 & $0 \%$ & 0 & $0 \%$ \\
\hline Ceftriaxone & 18 & $100 \%$ & 0 & $0 \%$ & 0 & $0 \%$ \\
\hline Erythromycin & 18 & $100 \%$ & 0 & $0 \%$ & 0 & $0 \%$ \\
\hline Clindamycin & 18 & $100 \%$ & 0 & $0 \%$ & 0 & $0 \%$ \\
\hline Vancomycin & 18 & $100 \%$ & 0 & $0 \%$ & 0 & $0 \%$ \\
\hline Tetracycline & 0 & $0 \%$ & 0 & $0 \%$ & 18 & $100 \%$ \\
\hline Linezolid & 18 & $100 \%$ & 0 & $0 \%$ & 0 & $0 \%$ \\
\hline Chloramphenicol & 18 & $100 \%$ & 0 & $0 \%$ & 0 & $0 \%$ \\
\hline Ceftriaxone was performed using Kirby-Bauer disc diffusion method for all isolates & \\
\hline
\end{tabular}

Consistent minimum inhibitory concentrations (MICs) were observed in most antibiotics. These include ampicillin $(\leq 0.25 \mu \mathrm{g} / \mathrm{L})$, penicillin $(\leq 0.12 \mu \mathrm{g} / \mathrm{L})$, clindamycin $(\leq 0.25 \mu \mathrm{g} / \mathrm{L})$, chloramphenicol $(\leq 10 \mu \mathrm{g} / \mathrm{L})$ and tetracycline $(\geq 16 \mu \mathrm{g} / \mathrm{L})$. The highest MIC value reported in erythromycin was $0.5 \mu \mathrm{g} / \mathrm{L}$ and the lowest was $\leq 0.25 \mu \mathrm{g} /$, which were all considered sensitive.

The highest MIC value reported for vancomycin was $4 \mu \mathrm{g} / \mathrm{L}$ and the lowest was $\leq 0.5 \mu \mathrm{g} / \mathrm{L}$, which were all considered sensitive. Linezolid was reported sensitive with MICs ranging from $1 \mu \mathrm{g} / \mathrm{L}$ to $2 \mu \mathrm{g} / \mathrm{L}$. The smallest inhibitory zone reported for ceftriaxone was $25 \mathrm{~mm}$ and the biggest was $33 \mathrm{~mm}$ which were all considered as sensitive.

\section{Gene based resistance of GBS isolates}

All isolates were tested for the presence of tetracycline resistance genes i.e. $\operatorname{tet}(\mathrm{M})$ and $\operatorname{tet}(0)$ with multiplex PCR, using previously described primers (Poyart et al., 2003 \& Zeng et al., 2006). In total, 16 isolates possessed tet( $(\mathrm{M})$ whereas tet( $(0)$ was found in none of the isolates, although they were all phenotypically resistant to tetracycline. Amplicons for tet( $M)$ have 347 base pairs and for tet( 0 ) have 548 base pairs (Poyart et al., 2003).

\section{Polysaccharide capsular typing}

Following the amplification and electrophoresis, 9 isolates presented with amplicons of 521 base pairs and 1 isolate with an amplicon sized 770 base pairs. An amplicon of 521 base pairs is associated with 
capsular polysaccharide la whereas 770 base pairs is associated with capsular type lb. Polysaccharide capsular type la was found in $9(50 \%)$ of isolates and $\mathrm{lb}$ was found in $1(5.5 \%)$ of the total isolates. The remaining eight (44.4\%) isolates could not be classified using PCR. Polysaccharide capsular type IX was not assessed in this study.

\section{Discussion}

The prevalence of GBS among pregnant women found in this study (5.7\%) was lower compared to what was reported in a similar study conducted in Windhoek, Namibia in 2016, whereby the prevalence of GBS colonisation was reported at $13.6 \% 2016^{6}$. Different recruitment centres were included in the current study, which comprise of a different population characteristic from the study by Engelbrecht et al. The prevalence in this current study is lower than the $31.6 \%$ found in Zimbabwe in $2000^{7}, 30.9 \%$ in South Africa in $2012^{17 ;}, 37 \%$ in South Africa in $2019^{8}$ and $21.2 \%$ in Malawi in $2010^{10}$.

The findings of this current study are similar to those reported in a Mozambican study, whereby a colonisation rate of $1.8 \%$ was obtained ${ }^{11}$. However, in the Mozambican study swabs were inoculated in Todd-Hewitt broth with only gentamycin $(8 \mu \mathrm{g} / \mathrm{ml}$ of agar) and the broth was sub-cultured onto human blood agar. The use of gentamycin alone without nalidixic acid can cause overgrowth of enterobacteriaceae organisms over GBS, hence reducing the growth of GBS. Furthermore, human blood used in preparation of blood agar might have contained inhibitory substances against the growth of GBS $^{11}$.

GBS colonisation was not associated with age, geographic location, marital status, educational level and employment status. This study revealed that $75.0 \%$ of colonised women were aged between $20-39$ years and $25.0 \%$ were aged 40 years and above. There was however no statistical significant association between GBS colonisation and age ( $P$ value 0.209 ). A similar study conducted at $\mathrm{Dr}$ George Mukhari hospital, South Africa found majority of GBS colonised women to be aged between 25 and 29 years, which was also not statistically significant $(P \text { value } 0.07)^{9}$. There was a significant association between maternal age and GBS colonisation in pregnant women screened at the maternity and children hospital in Makkah, Saudi Arabia ( $P$ value 0.002) 22 .

In the current study, $83.3 \%$ of colonised women were rural based and $16.7 \%$ were urban based. This difference was however not statistically significant ( $P$ value 0.708$)$. In a similar study conducted in $\mathrm{Dr}$ George Mukhari hospital, South Africa, more of the colonised women were dwelling in the urban areas ${ }^{9}$. This finding was however also not statistically significant ( $P$ value 0.08$)$. It was observed in this study that majority of GBS colonised women were not married (75.0\%), compared to married women (25.0\%). There was however no significant statistical association between GBS colonisation and marital status ( $P$ value 0.921). This agrees with the study conducted at Dr George Mukhari hospital, South Africa, which reported that the majority of colonised women were single, divorced or widowed followed by cohabiting women ( $P$ value 0.56$)^{9}$. In another study conducted in Windhoek by Engelbrecht et al., 2016, more single women 
were colonised compared to married women $(P \text { value } 0.315)^{6}$. Both findings were not statistically significant.

Furthermore, GBS was more prevalent in women who had no formal secondary education (58.3\%), with a decrease in colonisation observed as educational level increased, although this was not statistically significant ( $P$ value 0.333 ). A slight decrease in GBS colonisation with increase in educational level was also observed in the study conducted in Windhoek, although this was also not statistically significant ( $P$ value 0.729 ). Educational level was found to have a significant influence on GBS colonisation in pregnant women in the South African study (Dr George Mukhari hospital), whereby women with tertiary level of education were found to have lower colonisation compared to women with and without secondary education $(P \text { value }<0.0001)^{9}$.

GBS colonisation was higher in unemployed women than those employed as reported in this current study, with percentages of colonisation being $66.7 \%$ and $33.3 \%$ respectively. This was however not statistically significant ( $P$ value 0.234 ). On the contrary, a slightly large number of GBS colonised women was found to be employed women as revealed in the study conducted at $\operatorname{Dr}$ George Mukhari hospital ${ }^{9}$, and in Windhoek ${ }^{6}$. The relationship between employment and GBS colonisation was however not statistically significant in the Windhoek study $(P \text { value } 0.125)^{6}$, while in the South African study it was statistically significant $(P \text { value } 0.003)^{9}$.

Group B streptococcus colonisation did not appear to be linked to obstetric factors such as history of miscarriages and still births, as women with no history of still births and miscarriages were largely colonised (100\% and $83.3 \%$ respectively). These findings did not have any statistical significance ( $P$ value 0.613 and 0.471 respectively). However, GBS colonisation had shown to increase with parity, $50.0 \%$ in women with parity exceeding two, $33.3 \%$ in women with one or two previous deliveries and $16.7 \%$ in women without previous deliveries. This was however not statistically significant ( $P$. value 0.659$)$. In the Saudi Arabian study conducted at Makkah, a significant statistical association was found between parity and GBS colonisation ${ }^{22}$.

Similarly, GBS colonisation did not appear to be linked to history of miscarriages and still births in the South African study, as the carriage rate was greater in women who had no history of miscarriages and still births compared to the opposite. These were equally not statistically significant findings $(P$ value 0.33 and 0.24 respectively $)^{9}$. In contrast to the findings of this current study, a study by ${ }^{9}, 2016$ in South Africa reported that women with multiple deliveries exceeding two were less affected by GBS compared to women who had one to two deliveries and those with zero parity. However, there was no statistical significance $(P \text { value } 0.24)^{9}$.

In the current study, GBS showed sensitivity to penicillin, ampicillin, ceftriaxone, vancomycin, chloramphenicol and linezolid by $100 \%$. This correlates with the findings of the study done in Windhoek, where $100 \%$ susceptibility was reported to penicillin, ampicillin, ceftriaxone, vancomycin and linezolid. All isolates were found to be sensitive to clindamycin and erythromycin by $100 \%$. This does not correlate with 
findings of the Windhoek study, whereby $88.9 \%$ sensitivity and $11.1 \%$ resistance was reported for erythromycin, while for clindamycin $72.6 \%$ sensitivity, $18.8 \%$ intermediate sensitivity and $8.5 \%$ resistance was reported 6 .

Since only 18 GBS isolates were obtained from the current study, $100 \%$ susceptibility to clindamycin and erythromycin might not be a true reflection of the antimicrobial susceptibility patterns of GBS in the two regions, as a bigger number of isolates might have reflected a different picture. Furthermore, this current study revealed a $100 \%$ resistance to tetracycline, while the previous study has revealed $94.9 \%$ resistance to tetracycline and $5.1 \%$ susceptibility thereof. This differences may be attributable to the differences in the locations of the two studies and also different sample sizes.

The findings of our study are in correlation with another study conducted in Ayder referral hospital and Mekelle health centre, Mekelle, Northern Ethiopia, whereby GBS was reportedly $100 \%$ susceptible to penicillin, ampicillin, erythromycin, and vancomycin ${ }^{1}$. However, in the same study, intermediate GBS susceptibility was reported to chloramphenicol by $42.1 \%$ and ceftriaxone by $26.3 \%$, which opposes the findings of our study ${ }^{1}$.

On the contrary, our study findings are different from the findings of a similar study conducted in Ghandi memorial and Tikur Anbessa, Addis Ababa, Ethiopia, where GBS was found to be $55 \%$ susceptible to penicillin, $91 \%$ sensitive to ampicillin and all isolates except one were susceptible to erythromycin ${ }^{23}$. Increased resistance to penicillin in this area was attributable to a wide non-prescription use of penicillin due to weak drug control mechanisms ${ }^{23}$.

Another study conducted in Gabon, Central Africa to determine capsular type distribution and antimicrobial susceptibility of GBS in pregnant women found that all GBS isolates were susceptible to clindamycin, linezolid, vancomycin and benzyl penicillin which correlates with the findings of our study ${ }^{16}$. Fourteen isolates were however found intermediary susceptible to erythromycin, which contrasts the findings of our study. However, no inducible clindamycin resistance was found in the Gabon study, which draws a parallel between the two studies ${ }^{16}$.

In the neighbouring South Africa, a study conducted to assess the antimicrobial resistance of $S$. agalactiae isolated from pregnant women in Garankuwa found that all strains were $100 \%$ susceptible to penicillin, ampicillin and vancomycin, which is similarly demonstrated in our study ${ }^{23}$. The same study however found some strains to be resistant to erythromycin, clindamycin, tetracycline and chloramphenicol by $21.1 \%, 17.2 \%, 94.5 \%$ and $24.9 \%$ respectively, which distinguishes the two study findings ${ }^{23}$. In a comparable study conducted in Soweto, South Africa to determine the risk of GBS sepsis in infants exposed to HIV, all isolates were penicillin sensitive, and macrolide resistance was observed in $5.5 \%{ }^{25}$.

Generally, GBS has shown uniform sensitivity to penicillin, ampicillin, vancomycin, ceftriaxone and linezolid across many settings. Resistance to tetracycline was reported at $100 \%$ in our study compared to 
many previous studies, even though they also reported quite high percentages of resistance to tetracycline. Resistance to erythromycin and clindamycin was however not reported in our study, as opposed to other studies. These differences may be attributed to variations in capsular types common in different locations. In additions, fewer GBS isolates were obtained in the current study as compared to other studies, hence the differences in percentages of antimicrobial susceptibility.

None of the isolates phenotypically resistant to tetracycline presented with $\operatorname{tet}(0)$ gene, which confers resistance against tetracycline in addition to tet( $(M) g_{\text {gene }}{ }^{13}$. A related study which was conducted in Windhoek has found tet(M) in 114/117 GBS isolates and of these, 111 were tetracycline resistant as interpreted by the Vitek $2^{6}$. Based on that study, six of the isolates that possessed tet(M) did not appear to be phenotypically resistant to tetracycline ${ }^{6}$. This does not concur with our findings, as all isolates presenting with tet( $(\mathrm{M})$ were phenotypically resistant to tetracycline in our study. Only tetracycline resistance genes were inspected in our study, as all isolates from this study have only shown phenotypical resistance to tetracycline.

Our study found capsular type la to be common among the pregnant women screened. A similar study conducted to determine the antigenic distribution of $S$. agalactiae isolates from pregnant women at Garankuwa hospital in South Africa revealed that capsular type III was the most common capsular type (29.7\%), followed by la (25.6\%), II (15.6\%) IV (8.6\%), V (10.9\%) and Ib (8.6\%) ${ }^{17}$. These implies that the prominent capsular types associated with this population were III, la and II. In the current study, capsular type III was not picked up using PCR. Differences in geographical locations of the two studies may attribute to the differences in capsular types found in the two studies.

Another South African study conducted on pregnant mothers attending prenatal clinics in Soweto concluded that capsular type III was more associated with persistent colonisation throughout the study $(29 \%)$ than la $(18 \%)$ and $\mathrm{V}(6 \%)^{18}$. In a Zimbabwean study, the following capsular types were identified as follows: la, Ib, II, III and V at $15.7 \%, 11.6 \%, 8.3 \%, 38.8 \%$ and $24.0 \%$ respectively ${ }^{19}$, which corresponds with our findings. In Australia, GBS capsular type la, II and V were the leading causes of invasive infection ${ }^{26}$.

\section{Conclusions}

In the current study, the prevalence of GBS colonisation in women who attended antenatal screening at Okongo, Eenhana and Onandjokwe state hospitals was 5.7\%. Twelve women were colonised in total and of these, $25.0 \%$ carried GBS in their lower vagina and rectum, $58.0 \%$ in the lower vagina only and $17.0 \%$ in the rectum only. Our study findings have revealed that there was no significant statistical association between GBS colonisation and age, habitat, marital status, educational level and employment status. Similarly, there was also no statistically significant association between GBS colonisation and parity, history of still births and miscarriages.

Antimicrobial susceptibility was reported at $100 \%$ sensitive for ampicillin, penicillin, ceftriaxone, clindamycin, erythromycin, vancomycin, linezolid and chloramphenicol. Resistance to tetracycline was 
reported at $100 \%$. However, $100 \%$ susceptibility to erythromycin and clindamycin may be due to a smaller number of GBS isolates obtained from this study. The tetracycline resistance gene tet(M) was present in $88.9 \%$ of isolates and $11.1 \%$ had none, regardless of being phenotypically resistant to tetracycline. None of the isolates possessed detectable tet( 0 ) resistance gene.

Polysaccharide capsular type la was found in 9 (50\%) of isolates and $\mathrm{lb}$ was found in 1 (5.5\%) of the total isolates. The remaining 8 (44.4\%) isolates could not be classified using PCR.

\section{Methods}

\section{Study design}

This was a descriptive cross-sectional study which gathered descriptive data such as socio-economic, demographic characteristics and obstetric factors from participants.

\section{Study population}

The population comprised of pregnant women between 35 and 37 weeks gestation, who attended antenatal clinics at Onandjokwe, Eenhana and Okongo state hospitals between May and September 2018. Women who had taken antibiotics two weeks prior to the study, as well as those aged below 16 years were excluded from the study.

\section{Sample size}

The sample size was calculated based on the prevalence rate of GBS colonisation in pregnant women found in Windhoek, which was $13.6 \%^{6}$. using the following formula adopted from a prior study ${ }^{1}$. The expected sample size was 181 participants ( $n=181$ participants).

A total of 210 subjects were screened, 98 from Onandjokwe hospital, 93 from Eenhana hospital and 19 from Okongo hospital.

\section{Specimen collection}

A convenience sampling technique was used in this study and samples were collected consecutively. A lower vaginal and a rectal swab were collected from each participant by qualified clinicians using sterile cotton-tipped swabs. A lower vaginal swab was collected by inserting and brushing a sterile swab $2 \mathrm{~cm}$ into the vagina, periurethral area and labia. A rectal swab was collected by inserting a sterile swab $1 \mathrm{~cm}$ into the anus, rubbing the wall of the anal canal as described before ${ }^{12}$. The swabs were inserted into Amie's transport medium for preservation of bacteria. Each specimen was labelled with a unique identification. Specimens were transported at $2-8{ }^{\circ} \mathrm{C}$ to the laboratory. A cold chain protocol was observed during specimen transport and samples were cultured within an hour after reaching the laboratory.

\section{Specimen culturing}


Each swab was inoculated directly onto $5 \%$ Sheep blood agar with colistin and nalidixic acid (BCNA), followed by inoculation into Todd-Hewitt broth $(\mathrm{TH})$ supplemented with colistin and nalidixic acid. The culture plates and broths were incubated at $37^{\circ} \mathrm{C}$ in $\mathrm{CO}_{2}$ for $18-24$ hours. After incubation, BCNA culture plates were examined for presence of large, whitish-grey and translucent colonies with a narrow zone of $\beta$ haemolysis while the Todd-Hewitt broths were subcultured onto BCNA agar. Subcultured BCNA plates were incubated at $37^{\circ} \mathrm{C}$ in $\mathrm{CO}_{2}$ for $18-24$ hours and examined for presumptive GBS colonies. The Columbia CNA agar, Todd Hewitt broth, colistin and nalidixic acid antibiotics were obtained from Rochelle Chemicals and Laboratory Equipment, Johannesburg, South Africa.

\section{Isolation and identification of GBS}

Single colonies that presented with a narrow or large zone of $\beta$-haemolysis on the BCNA or TH-BCNA were subjected to the CAMP test for presumptive identification. S. agalactiae ATCC 12403 was used as a positive control and Streptococcus pyogenes ATCC 1244 as negative control. A known $\beta$-haemolytic toxin producing Staphylococcus aureus clinical isolate was used in this test. Presumptive GBS isolates were tested again using Vitek 2 before they were confirmed as GBS using molecular techniques by amplifying the $\operatorname{scpB}$ gene $^{20}$.

\section{DNA extraction}

DNA was extracted using the boiling method as described in a prior study ${ }^{4}$. Pure cultures of presumptive isolates were harvested from nutrient agar plates and emulsified in $200 \mu \mathrm{L}$ of DNA free water in respective Eppendorf tubes using sterile plastic loops, followed heating at $100{ }^{\circ} \mathrm{C}$ on the heating block for 15 minutes. Eppendorf tubes were centrifuged at 8000 revolutions per minute (rpm) for 10 minutes. The supernatant containing DNA was transferred to a clean labelled tube, and stored at $-20^{\circ} \mathrm{C}$ before use.

\section{PCR for identification}

A primer pair from Inqaba Biotechnical Industries (Pty) Ltd (Pretoria, South Africa) 5'ACAACGGAAGGCGCTACTGTTC-3' (forward primer) and 5'-ACCTGGTGTTTGACCTGAACTA-3' (reverse primer) which targeted the $s c p B$ gene was used for confirmation of $\mathrm{GBS}^{20}$. PCR reaction mixture was prepared as follows: $12 \mu$ l One Taq® Quick load® 2 X master mix with standard buffer, $10.5 \mu$ l nuclease free water, $1 \mu \mathrm{l}$ of forward and reverse primer, and $5 \mu \mathrm{l}$ DNA template, giving a final volume of $29.5 \mu \mathrm{l}$. The PCR conditions were as follows: 1 cycle at $94^{\circ} \mathrm{C}$ for 4 minutes (initial denaturation), 35 cycles at $93^{\circ} \mathrm{C}$ for 1 minute (denaturation), $57.6^{\circ} \mathrm{C}$ for 1 minute (annealing), $72{ }^{\circ} \mathrm{C}$ for 1 minute (elongation), 1 cycle at $72{ }^{\circ} \mathrm{C}$ for 7 minutes (further elongation) and $4{ }^{\circ} \mathrm{C}$ dwelling temperature using a BioRad thermal cycler (Johannesburg, South Africa).

The amplicons were electrophoresed on a $2 \%$ agarose gel electrophoresis with $1 \mathrm{xTris-Acetate}$ EDTA (TAE) buffer, at 110 volts for 45 minutes. A 1000 base pair (bp) DNA ladder, positive and negative control were included. The gel was visualised under the SYN GENE BIO IMAGING ultra violet system (Cambridge, United Kingdom). The sizes of amplicons were determined using the DNA molecular weight size standard.

\section{Antimicrobial sensitivity testing}


Antimicrobial sensitivity testing for sixteen confirmed isolates was performed using the Vitek 2 system (bioMerieux, Midrand, South Africa). This method employed gram positive antimicrobial sensitivity cards (AST-ST01). This card tested for penicillin, ampicillin, erythromycin, clindamycin, vancomycin, tetracycline, linezolid \& chloramphenicol Ceftriaxone was tested using the Kirby-Bauer disk diffusion method. Two isolates were tested using the Kirby-Bauer disc diffusion method against all antibiotics. Minimum inhibitory concentration (MIC) breakpoint results and disc zones were interpreted as stipulated by the Clinical Laboratory Standards Institute ${ }^{27}$.

\section{Multiplex PCR for gene-based resistance testing}

Specific oligonucleotide primers from Inqaba Biotechnical Industries (Pty) Ltd (Pretoria, South Africa) were used to screen for genotypic resistance $(\text { Table } 1)^{21 \& 13}$. The reaction mixture was prepared as follows: $12 \mu$ l One Taq® Quick load® 2 X master mix with standard buffer, $10.5 \mu$ l nuclease free water, $1 \mu \mathrm{l}$ of all forward and reverse primers, and $5 \mu \mathrm{LNA}$ template, giving a final volume of $31.5 \mu \mathrm{l}$. The multiplex PCR conditions were as follows: 1 cycle at $94^{\circ} \mathrm{C}$ for 4 minutes (initial denaturation), 35 cycles at $93^{\circ} \mathrm{C}$ for 1 minute (denaturation), $57.6^{\circ} \mathrm{C}$ for 1 minute (annealing), $72{ }^{\circ} \mathrm{C}$ for 1 minute (elongation), 1 cycle at $72{ }^{\circ} \mathrm{C}$ for 7 minutes (further elongation) and $4{ }^{\circ} \mathrm{C}$ dwelling temperature using a BioRad thermal cycler (Johannesburg, South Africa). The amplicons were electrophoresed on a $2 \%$ agarose gel electrophoresis with 1xTris-Acetate EDTA (TAE) buffer, at 110 volts for 45 minutes. A 1000 base pair (bp) DNA ladder, positive and negative control were included. The gel was visualised under the SYN GENE BIO IMAGING ultra violet system (Cambridge, United Kingdom). The sizes of amplicons were determined using the DNA molecular weight size standard.

Table 1

Oligonucleotide primers used in multiplex PCR for gene based resistance testing

\begin{tabular}{|c|c|c|c|}
\hline Primer & Target & Primer sequence $5^{\prime}-3^{\prime}$ & Size \\
\hline tetmS - F & $\operatorname{tet}(\mathrm{M})$ & GTCTTGCATATATACGCCTTTATAGTGGAGTACTACATTTACGAG & $374 \mathrm{bp}$ \\
\hline tetmA - R & $\operatorname{tet}(\mathrm{M})$ & CCACGTAATATCGTAGAAGCGGATCACTATCTGAG & \\
\hline tetoS - F & $\operatorname{tet}(0)$ & CGTATATATAGCGGAACATTGCATTTGAGGG & $548 \mathrm{bp}$ \\
\hline tetoA - R & $\operatorname{tet}(0)$ & CGGCTCTATGGACAACCCGACAGAAG & \\
\hline
\end{tabular}

\section{PCR for polysaccharide capsular typing}

Oligonucleotide primer pairs from Inqaba Biotechnical Industries (Pty) Ltd (Pretoria, South Africa) were used in capsular polysaccharide typing, in three different categories, i.e. type la - III, IV - VII and VIII $(\text { Table } 2)^{21}$. The PCR reaction mixture was prepared as follows: $12 \mu$ One Taq® Quick load® $2 \mathrm{X}$ master mix with standard buffer, $10.5 \mu \mathrm{l}$ nuclease free water, $1 \mu \mathrm{l}$ of all forward and reverse primers, and $5 \mu \mathrm{I}$ DNA template, giving a final volume of $35.5 \mu$ for type la - III \& IV - VII, and a final volume of $29.5 \mu$ for type VIII categories. 
The thermocycling conditions were as follows: 1 cycle at $94^{\circ} \mathrm{C}$ for 4 minutes (initial denaturation), 35 cycles at $93^{\circ} \mathrm{C}$ for 1 minute (denaturation), $58^{\circ} \mathrm{C}$ for 1 minute (annealing) (for type la - III), $59{ }^{\circ} \mathrm{C}$ (for type IV - VII) \& $56{ }^{\circ} \mathrm{C}$ (for type VIII), $72{ }^{\circ} \mathrm{C}$ for 1 minute (elongation), 1 cycle at $72{ }^{\circ} \mathrm{C}$ for 7 minutes (further elongation) and $4{ }^{\circ} \mathrm{C}$ dwelling temperature using a BioRad thermal cycler (Johannesburg, South Africa). The amplicons were electrophoresed on a $2 \%$ agarose gel electrophoresis with $1 \mathrm{x}$ Tris-Acetate EDTA (TAE) buffer, at 110 volts for 45 minutes. A 1000 base pair (bp) DNA ladder, positive and negative control were included. The gel was visualised under the SYN GENE BIO IMAGING ultra violet system (Cambridge, United Kingdom). The sizes of amplicons were determined using the DNA molecular weight size standard.

Table 2

Oligonucleotide Primers for polysaccharide capsular typing

\begin{tabular}{|c|c|c|c|}
\hline Primer & Target & Primer sequence & Size bp \\
\hline la-F & cps1aH & $5^{\prime}-$ GGTCAGACTGGATTAATGGTATGC - 3' & \multirow[t]{2}{*}{$521 \& 1,826 \mathrm{bp}$} \\
\hline la-R & cps1Ah & 5' - GTAGAAATAGCCTATATACGTTGAATGC - 3' & \\
\hline $\mathrm{lb}-\mathrm{F}$ & cps1bJ & $5^{\prime}$ - TAAACGAGAATGGAATATCACAAACC - 3' & \multirow[t]{2}{*}{770 bp } \\
\hline Ib-R & $c p s l b K$ & 5' - GAATTAACTTCAATCCCTAAACAATATCG - 3' & \\
\hline II-F & $\operatorname{cps} 2 K$ & 5' - GCTTCAGTAAGTATTGTAAGACGATAG - 3' & \multirow[t]{2}{*}{$397 \mathrm{bp}$} \\
\hline II-R & $\operatorname{cps} 2 \mathrm{~K}$ & 5' - TTCTCTAGGAAATCAAATAATTCTATAGGG - 3' & \\
\hline III-F $F^{a}$ & cps1a/2/3I & $5^{\prime}$ - TCCGTACTACAACAGACTCATCC - 3' & \multirow[t]{2}{*}{$1,826 \mathrm{bp}$} \\
\hline III-R $\mathrm{R}^{\mathrm{a}}$ & cps1a/2/3J & $5^{\prime}$ - AGTAACCGTCCATACATTCTATAAGC - 3' & \\
\hline IV-F & $\operatorname{cps} 4 N$ & 5' - GGTGGTAATCCTAAGAGTGAACTGT - 3' & \multirow[t]{2}{*}{$578 \mathrm{bp}$} \\
\hline IV-R & $\operatorname{cps} 4 N$ & 5' - ССTCCССАATTTCGTCCATAATGGT - 3' & \\
\hline V-F & $\operatorname{cps} 50$ & $5^{\prime}$ - GAGGCCAATCAGTTGCACGTAA - 3' & \multirow[t]{2}{*}{$701 \mathrm{bp}$} \\
\hline V-R & $\operatorname{cps} 50$ & 5' - ААССТТСТССТТСАСАСТААТССТ - 3' & \\
\hline VI-F & cps6l & 5' - GGACTTGAGATGGCAGAAGGTGAA - 3' & \multirow[t]{2}{*}{$487 \mathrm{bp}$} \\
\hline VI-R & cps6l & 5' - CTGTCGGACTATCCTGATGAATCTC - 3' & \\
\hline VII-F & cps7M & $5^{\prime}$ - CCTGGAGAGAACAATGTCCAGAT - 3' & \multirow[t]{2}{*}{$371 \mathrm{bp}$} \\
\hline VII-R & $c p s 7 M$ & 5' - GCTGGTCGTGATTTCTACACA - 3' & \\
\hline VIII-F & cps8J & 5' - AGGTCAACCACTATATAGCGA - 3' & \multirow[t]{2}{*}{$282 \mathrm{bp}$} \\
\hline VIII-R & cps8J & 5' - TCTTCAAATTCCGCTGACTT - 3' & \\
\hline Poyart & al., 2007 & & \\
\hline
\end{tabular}

\section{Abbreviations}




\begin{tabular}{|c|c|}
\hline A & Adenine \\
\hline ATCC & American Type Culture Collection \\
\hline BBB & Blood Brain Barrier \\
\hline BCNA & Columbia Sheep Blood with Colistin and Nalidixic acid \\
\hline BibA & GBS immunogenic bacterial adhesion \\
\hline C & Cytosine \\
\hline CAMP & Christie, Atkins, Munch and Petersen test \\
\hline CDC & Centres for Diseases Control and Prevention \\
\hline CLSI & Clinical Laboratory Standards Institute \\
\hline DNA & Deoxy Ribonucleic Acid \\
\hline EOD & Early Onset Disease \\
\hline Fbs & Fibrigogen binding proteins \\
\hline G & Guanine \\
\hline GBS & Group B Streptococcus \\
\hline HIV & Human Immuno-Deficiency Virus \\
\hline IAP & Intrapartum Antibiotic Prophylaxis \\
\hline Lmb & Laminin binding protein \\
\hline LOD & Late Onset Disease \\
\hline LVS & Lower Vaginal Swab \\
\hline MIC & Minimum Inhibitory Concentration \\
\hline NIP & Namibia Institute of Pathology \\
\hline NUST & Namibia University of Science and Technology \\
\hline PCR & Polymerase Chain Reaction \\
\hline rRNA & Ribosomal Ribonucleic Acid \\
\hline S. agalactiae & Streptococcus agalactiae \\
\hline S. aureus & Staphylococcus aureus \\
\hline SBA & Sheep Blood Agar \\
\hline $\operatorname{scpB}$ & Group B streptococcal C5a peptidase \\
\hline
\end{tabular}

TH Todd Hewitt 


\begin{tabular}{|ll|}
\hline A & Adenine \\
\hline SfbA & Streptococcal fibronectin binding protein \\
\hline SPSS & Statistical Package for Social Sciences \\
\hline S. pyogenes & Streptococcus pyogenes \\
\hline T & Thymine \\
\hline TAE & Tris-Acetate EDTA buffer \\
\hline Taq & Polymerase enzyme produced by Thermophilus aquaticus \\
\hline TH Todd Hewitt & \\
\hline
\end{tabular}

\section{Declarations}

\section{Ethics approval and consent to participate}

Ethical approval was granted by the Ministry of Health and Social Services (MoHSS), Namibia. Written informed consent was obtained from each participant.

\section{Consent for publication}

Not applicable.

\section{Availability of data and material}

The datasets used and/or analysed during the current study are available from the corresponding author on reasonable request.

\section{Competing interests}

The authors declare that they have no competing interests.

\section{Funding}

Funding for this study was provided by the Namibia Institute of Pathology (NIP) and Namibia University of Science and Technology (NUST).

\section{Authors' contribution}

All authors the authors significantly contributed to the conduct of the study. ELH, MM and SRM conceptualised the research and designed the work. SRM supervised the study and ELH collected data and cultured specimens. ELH and MM carried the molecular screening of isolates and all authors contributed to the drafting of the manuscript and revision and approved it. 


\section{Acknowledgements}

We would like to thank NIP and NUST for financial support. The Department of Health Sciences, Medical Laboratory Sciences Programme for general support during the conduct of the study. Our sincere thanks go to all the women who participated in the study and the nurses from the study hospitals who helped in the collection of samples for the study.

\section{References}

1. Alemseged G, Niguse S, Hailekiros H, Abdulkadir M, Saravanan M, Asmelash T. Isolation and antimicrobial susceptibility pattern of Group B streptococcus among pregnant women attending antenatal clinics in Ayder Referral Hospital and Mekelle Health Centre, Mekelle, Northern Ethiopia. BioMed Central. 2015;8:1-8.

2. Belard S, Toepfner N, Capan-Melser M, Mombo-Ngoma G, Zoleko-Manego R, Groger M,... Berner R. Streptococcus agalactiae capsular type distribution and antimicrobial susceptibility in pregnant women in Gabon, Central Africa. Sci Rep. 2015;5:1-4.

3. bioMerieux. (2014). Vitek® 2: Healthcare. Retrieved from http://www.biomerieuxusa.com/clinical/vitek-2-healthcare.

4. Bolukaoto JY, Monyama CM, Chukwu MO, Lekala SM, Nchabeleng M, Maloba MRB,... Moyo SR. Antibiotic resistance of Streptococcus agalactiae isolated from pregnant women in Garankuwa, South Africa. BioMed Central Research Notes. 2015;8:1-7.

5. Centre for Diseases Control and Prevention. (2010). Algorithm for screening Group B Streptococcus colonisation. Retrieved from: https://www.cdc.gov/Groupbstrep/guidelines/algorithms-tables.html.

6. Chukwu MO, Mavenyengwa RT, Monyama CM, Bolukaoto JY, Lebelo SL, Maloba MRB, Nchabeleng M, Moyo SR. Antigenic distribution of Streptococcus agalactiae isolates from pregnant women at Garankuwa hospital - South Africa. Germs. 2015;5(4):125-33.

7. Clinical and Laboratory Standards Institute. Performance standards for antimicrobial susceptibility testing. 28th ed. Wayne: Clinical and Laboratory Standards Institute; 2018.

8. Cutland CL, Schrag SJ, Thigpen MC, Velaphi SC, Wadula J, Adrian PV,... Madhi SA. Increased risk for Group B streptococcus sepsis in young infants exposed to HIV, Soweto, South Africa, 2004-2008. Emerg Infect Dis. 2015;21(4):638-45.

9. de Steenwinkel FDO, Tak HV, Muller AE, Nouwen JL, Oostvogel PM, Mocumbi SM. Low carriage rate of Group B streptococcus in pregnant women in Maputo, Mozambique. Tropical Medicine International Health. 2008;13(3):427-9.

10. Dmitrieve A, Suvorov A, Shen AD, Yang YH. Clinical diagnosis of Group B streptococci by $s c p B$ gene based PCR. Indian J Med Res. 2004;119:233-6.

11. Doran KS, Nizet V. Molecular pathogenesis of neonatal Group B streptococcal infection: No longer in its infancy. Mol Microbiol. 2004;54(1):23-31. 
12. Engelbrecht F, Moyo SR, Maposa I, Mukesi M, Khan S. The antimicrobial susceptibility and genebased resistance of Streptococcus agalactiae (Group B streptococcus) in pregnant women in Windhoek (Khomas region), Namibia. Medical Technology SA. 2016;30(2):9-14.

13. Engelbrecht F. (2015). The antimicrobial susceptibility and gene-based resistance of Streptococcus agalactiae (Group B streptococcus) in pregnant women in Windhoek (Khomas region), Namibia (Published master's thesis). Cape Peninsula University of Technology, Bellville.

14. Gray KJ, Kafulafula G, Matemba M, Kamdolozi M, Membe G, French N. Group B streptococcus and HIV infection in pregnant women, Malawi, 2008-2010. Emerg Infect Dis. 2011;17(10):1932-5.

15. Gygax SE, Schuyler JA, Kimmel LE, Trama JP, Mordechai E, Adelson ME. Erythromycin and clindamycin resistance in Group B streptococcal clinical isolates. American Society for Microbiology. 2006;50(5):1875-7.

16. Heelan JS, Hasenbein ME, McAdam AJ. Resistance of Group B streptococcus to selected antibiotics, including erythromycin and clindamycin. J Clin Microbiol. 2004;42(3):1263-4.

17. Joachim A, Matee MI, Massawe FA, Lyamuya EF. Maternal and neonatal colonisation of Group B streptococcus at Muhimbili National Hospital in Dar es Salaam, Tanzania: Prevalence, risk factors and antimicrobial resistance. BioMed Central Public Health. 2009;9:1-7.

18. Khan MA, Faiz A, Ashshia AM. Maternal colonisation of Group B Streptococcus: Prevalence, associated factors and antimicrobial resistance. Ann Saudi Med. 2015;35(6):423-7.

19. Kwatra G, Adrian PV, Shiri T, Buchmann EJ, Cutland CL, Madhi SA. Capsular type-specific acquisition and loss of Group B streptococcus recto-vaginal colonisation in late pregnancy. Plos One. 2014;9(6):1-9.

20. Mavenyengwa RT, Afset JE, Schei B, Berg S, Caspersen T, Bergseng H, Moyo SR. Group B streptococcus colonisation during pregnancy and maternal-fetal transmission in Zimbabwe. Acta Obstet Gynecol Scand. 2009;89(2):250-5.

21. Mavenyengwa RT, Moyo SR, Nordbo SN. (2010). Streptcoccus agalactiae colonisation and correlation with HIV-1 and HBV seroprevalence in pregnant women from Zimbabwe. European Journal of Obstetrics \& Gynaecology and Reproductive Biology, 150(2010), 34-38.

22. Mavenyengwa RT, Maeland JA, Moyo SR. Serotype markers in a Streptococcus agalactiae collection from Zimbabwe. Indian Journal of Medical Microbiology. 2010;28(4):313-9.

23. Monyama MC, Bolukaoto JY, Chukwu MO, Maloba MRB, Moyo SR, Mavenyengwa RT,... Lebelo SL. Group B streptococcus colonisation in pregnant women at Dr. George Mukhari Hospital, South Africa. Southern African Journal of Infectious Diseases. 2016;1(1):1-5.

24. Moyo SR, Mudzori J, Tswana SA, Maeland J. Prevalence, capsular type distribution, anthropometric and obstetric factors of Group B streptococcus (Streptococcus agalactiae) colonisation in pregnancy. The Central African Journal of Medicine. 2000;46(5):115-20.

25. Poyart C, Jardy L, Quesne G, Berche P, Trieu-Cout P. Genetic basis of antibiotic resistance in Streptococcus agalactiae strains isolated in a French hospital. Antimicrobial agents Chemotherapy. 2003;47(2):794-7. 
26. Poyart C, Tazi A, Reglier-poupet H, Billoet A, Tavares N, Raymond J, Trieu-Cuot P. Multiplex PCR assay for rapid and accurate capsular typing of Group B streptococci. J Clin Microbiol. 2007;45(6):1985-8.

27. Teatero S, McGeer A, Low DE, Li A, Demczuk W, Martin I, Fittipaldia N. Characterisation of invasive Group B streptococcus strains from the greater Toronto area, Canada. J Clin Microbiol. 2014;52(5):1441-7.

28. Woldu ZL, Teklehaimanot TG, Waji ST, Gebremariam MY. (2014). The prevalence of Group B streptococcus recto-vaginal colonisation and antimicrobial susceptibility pattern in pregnant mothers at two hospitals of Addis Ababa, Ethiopia. Reproductive Health, 11.

29. Zhao Z, Kong F, Zeng X, Gidding HF, Morgan J, Gilbert GL. Distribution of genotypes and antibiotic resistance genes among invasive Streptococcus agalactiae (Group B streptococcus) isolates from Australasian patients belonging to different age groups. European Society of Clinical Microbiology Infectious Diseases. 2008;14:260-7.

30. Zeng X, Kong F, Wang H, Darbar A, Gilbert G, L. Simultaneous detection of nine antibiotic resistancerelated genes in Streptococcus agalactiae using multiplex PCR and reverse line blot hybridization assay. American Society for Microbiology. 2006;50(1):204-9. 